Published in final edited form as:

Ann Behav Med. 2012 June ; 43(3): 320-329. doi:10.1007/s12160-012-9344-y.

\title{
Using the Interdependence Model to Understand Spousal Influence on Colorectal Cancer Screening Intentions: A Structural Equation Model
}

\author{
Sharon Manne, Ph.D., \\ Deborah Kashy, Ph.D., \\ Michigan State University, East Lansing, MI, USA \\ David S. Weinberg, M.D., \\ Fox Chase Cancer Center, Philadelphia, PA, USA \\ Joseph A. Boscarino, Ph.D., and \\ Geisinger Health Systems, Danville, PA, USA \\ Deborah J. Bowen, Ph.D. \\ Boston University, Boston, MA, USA \\ Sharon Manne: Mannes|@umdnj.edu
} UMDNJ/Cancer Institute of New Jersey, 195 Little Albany Street, New Brunswick, NJ, USA

\begin{abstract}
Background-Although it is widely thought that the marital relationship plays a role in individuals' decisions to have colorectal cancer screening, few studies have evaluated partner influences.
\end{abstract}

Purpose-We evaluated the role of marital relationship factors such as a relational perspective on the frequency of spouse discussions about screening and screening intentions. Individual-level factors were also evaluated.

Methods-One hundred sixty-eight couples with both members non-adherent with screening completed measures of perceived risk, screening benefits and barriers, marital quality, relational perspective, discussion frequency, and screening intentions.

Results-Couples' attitudes about screening were interdependent and one partner's attitudes and behavior were associated with the other partner's intention. There was also evidence of joint effects in that intentions were associated with both one's partner's attitudes and one's own attitudes.

Conclusions-Colorectal screening intentions are associated with both partners' attitudes as well as whether or not couples have discussed screening with one another.

\section{Keywords}

Interdependence model; Couples; Colorectal cancer screening intentions; Actor-partner independence model

\footnotetext{
(c) The Society of Behavioral Medicine 2012

Correspondence to: Sharon Manne, Mannesl@umdn j.edu.

Conflict of Interest The authors have no conflict of interest to disclose.
} 


\section{Introduction}

Colorectal cancer is the second leading cause of cancer deaths in the USA. The American Cancer Society estimates that there will be about 141,210 new cases of colorectal cancer diagnosed in 2011 in the USA [1]. Although the death rate has been declining for the past 15 years, this disease will cause about 49,380 deaths in 2011 [1]. Colorectal cancer mortality rates can be reduced substantially through screening via fecal occult blood tests and sigmoidoscopy. While uptake rates for colorectal cancer screening have been increasing, participation in screening remains relatively low, particularly in comparison with other cancers and when considering prevention objectives set forth in Healthy People 2010 [2]. Novel approaches for improving screening rates need to be developed and rigorously evaluated.

Among the broad set of demographic, knowledge, and attitudinal factors which have been examined as possible motivators for colorectal cancer screening, the influence of one's significant other (e.g., spouse or partner) is a little-studied but possibly important factor. Several studies have indicated that married individuals have higher colorectal cancer screening rates than single persons [3]. The few studies that have evaluated the mechanisms of partner influence have examined general family influence rather than focusing on the significant other. Greater family support for screening has been shown to be a correlate of greater colorectal cancer screening uptake among average risk individuals [4], and family recommendation for screening, particularly from the affected family member, is a correlate of uptake among intermediate risk family members $[5,6]$. Family communication about screening has also been found to be a correlate of other types of cancer screening and surveillance practices such as sun protection among family members of individuals with melanoma [7].

Evidence for the role of the marital relationship also comes from the literature on the correspondence between couples' health behaviors which has suggested a strong correspondence between spouses' health practices such as diet, smoking, drinking, and physical activity [8-10]. Although assortative mate selection may contribute to this correspondence, it may also reflect the influence spouses have on each other in terms of health-enhancing or health-compromising behaviors. There are little data available on the correspondence between partners' colorectal cancer screening practices. Our own data suggest the correspondence between couples' screening practices is 65\% (Manne and Boscarino, unpublished data). Thus, the limited studies on spouse influence and screening suggest that spouses may have a role in decisions to undergo screening.

Lewis and colleagues' [11, 12] conceptualization of the interdependence model [13-15] proposes that couples have a significant influence on one another when deciding to engage in behavioral changes. The theory examines the processes of influence-that is, the degree to which couples cooperate or work together to accomplish a goal. The interdependence model separates actor, partner, and joint effects. Actor effects are those effects due to the person. Partner effects are the influences one partner has on the other. Joint effects are those behaviors that are influenced by both oneself and one's partner. Lewis and colleagues [12] suggest that joint effects are stronger than the other effects because health behavior changes occur in the context of a close relationship. There are two key constructs in this model that are relevant to the proposed study. The first construct is interdependence, which is defined as the effects that interacting partners have on each other's motives, preferences, behaviors, and health outcomes [15]. Interdependence suggests that the partner's role in health behavior change needs to be identified. The second construct is transformation of motivation. Transformation of motivation involves partners changing reasons for making a health behavior change from an individual motivation to a relational motivation. One example is 
feeling that the health behavior change may benefit the quality of the marital relationship. This process involves adopting a relational perspective on the health threat by interpreting the health threat as meaningful for the partner and the relationship.

Unfortunately, there has been relatively little attention given to the interdependence model and health behavior change and almost no attention paid to the role of the marital relationship in cancer screening decisions. The available research has been devoted to understanding mechanisms of partner influence on the other partner's health behaviors. This literature has fallen into two areas, the first of which includes identification and categorization of strategies couples use to support and influence the other partner to undertake a health behavior change [11, 16-18]. Influence and communication strategies have been categorized into three dimensions, (1) direct (state how it is important to you) versus indirect (hints), (2) positive (offer to make the change along with the spouse) versus negative (try to make the spouse feel guilty), and (3) bilateral (discuss the situation) versus unilateral (withdraw). The second body of work concerns the role of couples' social influence strategies in health behavior change. The use of positive, direct, and bilateral health related influence tactics predicts behavior change [19] while the effects of negative, indirect, and unilateral methods on behavior change have been inconsistent with some studies showing adverse effects of these tactics [17] and some studies suggesting positive effects [20].

Less is known about the associations between individual and relationship factors that may influence the transformation of motivation for behavioral change from an individual-to a dyadic-level motivation for health behavior change. There are two individual factors, risk and perceived benefits versus barriers to the behavior change, and one relationship factor, relationship quality, which we focus on in this study. The interdependence model posits that perceptions about the health threat and relationship functioning predict spouses' transformation of motivation [12], but the role of these variables has not been studied. Greater perceived risk of colorectal cancer may be a cue for each partner to consider the health event (colorectal cancer) in terms of its meaning to the relationship. Similarly, perceiving more benefits to engaging in the health behavior may also motivate partners to adopt a relational perspective regarding possible benefits of engaging in the behavior [12]. Higher quality relationships may also foster partners to think of health behaviors in terms of their impact on the relationship [12].

The current study addressed this gap in the literature by evaluating a model of the associations between individual-level factors (perceived risk, benefits and barriers to colorectal cancer screening, perceptions of marital quality), adopting a relational perspective on colorectal cancer screening, discussion with one's spouse about colorectal cancer screening, and, ultimately, with colorectal intentions. We studied couples who were not adherent with screening in order to evaluate spouse influence strategies and discussions about screening in a situation where both partners needed to make the behavioral change. This decision offered the opportunity to look at joint influences. Thus, intentions rather than screening behaviors were selected as the outcome. The proposed model is shown in Fig. 1. Based on the interdependence model, we proposed that individuals with greater perceived risk, more perceived screening benefits relative to perceived barriers (decisional balance) and higher perceived marital quality would be more likely to adopt a relational perspective concerning screening. A greater relational perspective, in turn, would predict a greater likelihood that screening would be discussed with one's spouse, and discussion would predict the other spouse's screening intentions. 


\section{Methods}

\section{Participants}

Participants were recruited from Knowledge Networks, a company that specializes in innovative probability-based online research. Knowledge Networks are leaders in Internet research with an extensive, ongoing program of methodological research that bridges the gap between statistical theory, methodology, and real-world application (see below for more details). Data for the present study were collected between June and July, 2010. Inclusion criteria were (1) 50 years of age and older; (2) married and living with a partner at the same residence; (3) both partners at average risk for colorectal cancer, defined as asymptomatic, without a personal and family history of colorectal cancer or colorectal polyps, inflammatory bowel disease, or a family history of familial adenomatous polyposis, hereditary non-polyposis colorectal cancer or colorectal cancer in more than one first degree relative; (4) both partners willing to participate in the study; (5) both partners were nonadherent with standard colorectal cancer screening recommendations. Non-adherent was defined as no completion of three-card fecal occult blood test in the last 12 months, flexible sigmoidoscopy in the past 5 years, or routine colonoscopy in the past 10 years by self-report.

Of the 4,801 Knowledge Networks panel members queried for participation, 3,711 (33\%) completed the screening survey. Of these 3,711, 255 met the study eligibility criteria (7\%). Reasons for ineligibility were: either partner less than 50 years $(n=31)$, not at average risk for colorectal cancer $(n=961)$, or either partner adherent with colorectal cancer screening $(n=1,052)$, one partner did not pass the survey on to the other partner or the partner did not complete one or more items of the screening survey $(n=1,667)$

Of the 255 couples meeting eligibility, 251 (98.4\%) agreed to participate. One hundred ninety couples completed the survey $(75 \%)$. Twenty-two couples consented, but did not complete a sufficient amount of the baseline survey to be included in the analyses. Thus, the final sample included 168 couples. Comparisons of the 168 participating couples versus the couples who did not participate in the final sample did not yield significant differences on any available data (i.e., either partner's age, education, ethnicity, and income).

\section{Procedures}

Participants were identified by Knowledge Networks from their KnowledgePanel®, the only online panel based on a representative sample of the full US population. Knowledge Networks selects households for recruitment by using random digit dialing or by using address-based sampling. Panel members are recruited by telephone and mail surveys, and households are provided with access to the Internet and hardware if needed. The Knowledge Networks sample is demographically comparable with samples that are obtained using random-digit dialing [30]. Once participants have been selected for the panel, responding to any given survey is voluntary, and the provision of internet service is not dependent on completion of any specific survey. Even though panel members complete surveys regularly, those who complete more surveys do not differ from those members who complete fewer [31].

The households are sent an advance mailing informing them that they have been selected to participate in KnowledgePanel ${ }^{\circledR} 7$ to 9 days prior to the recruitment telephone call. Following the advance letter, the telephone recruitment process begins for all sampled phone numbers. Cases sent to telephone interviewers are dialed up to 90 days, with at least ten dial attempts on cases where no one answers the phone, and on phone numbers known to be associated with households. Experienced interviewers conduct all recruitment interviews. The recruitment interview begins with the interviewer informing the household member that 
they have been selected to join KnowledgePanel®. Once a person is recruited to the panel, they are contacted primarily by e-mail. For those Panel members without Internet access, a laptop is custom configured with individual email accounts so that it is ready for immediate use by the household members. Knowledge Networks maintains a telephone technical support line and will, when needed, provide on-site installation. The support department also contacts household members who do not respond to survey invitations and attempts to restore contact and cooperation. Panel members who have Internet access provide Knowledge Networks with their email accounts and their weekly surveys are sent to that email account. For all new panel members, demographic information such as gender, age, race/ethnicity, income, and education are collected in a follow-up survey. The demographic information already available was used as an initial screener of age and marriage status eligibility for this study.

When surveys are assigned to KnowledgePanel® members, they receive notice in their password protected e-mail account that the survey is available for completion. Participants follow the link to the survey and acknowledge reading through the online consent document before proceeding to the survey. Surveys are self-administered online and are accessible any time of day for a designated period of 6 weeks. If after 6 weeks a survey was not completed, the participant was considered a passive refuser.

For the present study, Knowledge Networks randomly selected one person per household for the initial electronic mail solicitation/contact. Thus, the first person could be the husband or wife. After the first person completed the screening questions, they were asked to hand off the screening questions to their spouse so the spouse could complete them if they confirmed they had a spouse over 50 years of age. In terms of sequencing the survey completion, the spouse who completed the screening first was allowed access to the survey, and then was asked to hand off to the second spouse.

\section{Measures}

Demographics-Age, ethnicity, income, education, employment status, and whether participants had health insurance were assessed.

Perceived Risk—Five items assessed personal risk for colorectal cancer: (1) percent likelihood of developing colorectal cancer, (2) chances compared with individuals the same age ( $1=$ much lower to $5=$ much higher), (3) chances of developing colorectal cancer if he/she does not have screening (1=almost zero to $7=$ almost certain), (4) chances of developing colorectal cancer if he/she does not have screening ( $0 \%$ to $100 \%$ ); (5) If I don't have colorectal cancer screening, I think I am ( $1=$ unlikely to develop colorectal cancer; $2=$ likely to develop colorectal cancer). A scale score was computed by first standardizing the five items across the sample, and then computing the mean of the standardized scores. Internal consistency as calculated by Cronbach's alpha were 0.90 and 0.88 for husband and wife, respectively.

Benefits and Barriers of Screening-This 28-item scale was based on Rakowski and colleagues [21] and our previous work [6]. The scale consists of 9 benefits and 19 barriers rated on a Likert scale from strongly agree [5] to strongly disagree [1]. A decisional balance score was constructed by computing the difference between the mean benefits and mean barriers such that higher scores indicated a more positive orientation. Internal consistency as calculated by Cronbach's alpha were 0.92 and 0.89 for husband and wife, respectively.

Marital Quality-The Brief Dyadic Adjustment scale [22] is a six-item scale assessing marital quality. The scale is an abbreviated version of the original 32-item scale and has 
high correspondence with this scale [22]. The score was a sum of all items. Higher scores indicate greater satisfaction. Internal consistency as calculated by Cronbach's alpha were 0.81 and 0.86 for husband and wife, respectively.

Relational Perspective-We modified the Thinking Beyond Oneself scale adapted from Rakowski and colleagues [21] to assess an individual's relational perspective on screening (i.e., transformation of motivation). The adapted scale consisted of the sum of responses on four items (e.g., "Having screening is important for both my spouse and I", "Whether my partner has colorectal cancer screening could impact my future too", "If my spouse plans to have a colorectal cancer screening test, I would say that is a good idea", and "I can think of reasons having screening is important to my spouse") which were rated on a Likert scale from strongly agree [5] to strongly disagree [1]. Internal consistency as calculated by Cronbach's alpha were 0.85 and 0.84 for husband and wife, respectively.

Discussions with Partner About Screening-Participants were asked how frequently they discussed screening with their spouse in the past 6 months on a 4-point scale (never, once, twice, and more than two times).

Screening Intentions-Participants were asked to answer four questions regarding intentions to have screening in the next year ("Do you intend to have a colorectal cancer test of any kind in the next year?" "Do you intend to ask your doctor about colorectal cancer screening in the next year?" "How likely do you think it is that you will try to make an appointment to have a colorectal cancer screening test in the next year?" "If your doctor recommends a colorectal cancer screening test, how likely are you to follow through with his or her recommendation in the next year?") The items were rated on 7-point Likert scales ( $1=$ not at all likely to $7=$ extremely likely) and summed. Internal consistency as calculated by Cronbach's alpha were 0.90 and 0.81 for husband and wife, respectively.

\section{Analytic Approach}

A path model predicting colorectal cancer screening intentions for the 168 couples was estimated using AMOS (version 19). In this model, we tested Lewis et al.'s [12] interdependence model of couple communal coping and behavior change within the framework of the actor-partner interdependence model [23]. According the actor-partner interdependence model, when dyads are comprised of interdependent individuals, each individual's outcomes may be a function of both their own inputs (i.e., an actor effect) and their partner's inputs (i.e., a partner effect). Thus, in constructing our model we first specified both actor and partner paths from each predictor to each outcome, and then we trimmed non-significant paths and computed chi-square difference tests to evaluate whether the simplifications significantly worsened model fit.

\section{Results}

\section{Preliminary Analysis}

Characteristics of the study sample are shown in Table 1, and means, standard deviations, and Pearson correlations for each of the measured scales are shown in Table 2.

\section{Structural Equation Model Results}

Our initial model included dyadic adjustment, perceived colorectal cancer risk, and decisional balance as purely exogenous variables, as in Fig. 1. However, marital quality was not significantly related to any of the other variables in the model beyond its cross-partner correlation (i.e., it did not predict any of the endogenous variables and it did not correlate significantly with the other exogenous variables). We therefore dropped marital quality from 
the model and used the simplified model depicted in Fig. 2. In addition, we also examined whether the path coefficients, variances, and correlations differed by gender, and with only one exception (discussed below), equality constraints across husbands' and wives' data did not significantly worsen model fit. This aspect of the analysis can be seen in the figure by noting that the parameter estimates for each path are generally the same for husbands and wives. Finally, although not depicted in the figure, the model included residual variances for each of the endogenous variables, and in all cases these residual variances were allowed to correlate between husbands and wives (correlations of the residuals across partners: relational perspective $-r=0.57, p<0.01$; discussion $-r=0.92, p<0.01$; screening intention— $r=0.64, p<0.01$ ).

Model fit for Fig. 2 was quite good: $\chi^{2}(35)=39.73, p=0.27$, RMSEA=0.03, CFI=0.99, and $P_{\text {close }}=0.81$. Husbands' and wives' decisional balance (i.e., the degree to which the individual believes that having screening possesses more benefits than barriers) and perceived risk of developing colorectal cancer were initially allowed to predict both their own reported relational perspective, discussion frequency, and screening intention and their partners' reported relational perspective, discussion frequency, and screening intention. As the figure shows, a person's own perceived risk of colorectal cancer showed significantly positive direct associations with that person's relational perspective (parameter estimate $=0.10$ for both husband and wife) and that person's reports of discussions about screening (parameter estimate $=0.09$ for both husband and wife) suggesting that individuals who felt they were at higher risk for colorectal cancer also tended to see more benefits of colorectal cancer screening for their spouse and were more likely to discuss colorectal cancer screening with their spouse. However, the person's own perceived risk did not have a direct association with that person's screening intention. In addition, perceived risk did not show evidence of partner effects for any of the endogenous variables, suggesting that an individual's perception of his or her own colorectal cancer risk did not predict the person's partner's outcomes (except via their indirect associations with colorectal cancer screening discussion via relational perspective).

Similarly, the individual's decisional balance predicted only his or her own outcomes and did not predict his or her partner's outcomes. Specifically, individuals who reported more screening benefits than barriers tended to report more benefits for their spouse and relationship (parameter estimate $=0.60$ for husband and wife) and reported higher screening intentions for themselves (parameter estimate $=0.51$ for husband and wife). Thus, decisional balance showed evidence of a direct association with screening intention as well as indirect associations.

Moving to the next set of variables in the model, both actor and partner effects on frequency of screening discussions emerged for individuals who reported a higher relational perspective. Husbands who had higher relational perspective scores also tended to report more frequent screening discussions with their wives (parameter estimate $=0.14$ for husband and wife) and their wives also reported more frequent screening discussion (parameter estimate $=0.14$ for husband and wife). This pattern of findings in which the actor and partner effects are virtually identical has been called a couple-oriented pattern [23], which is reminiscent of what Lewis and colleagues [11] term a joint effect. Notably, there were no direct associations between relational perspective and screening intentions once the indirect effects were controlled.

Finally, discussion frequency was a significant predictor of screening intentions. For this part of the model, there was no evidence of actor effects, and so individuals who reported engaging in more discussions of screening did not have significantly higher screening intentions. Instead, as predicted by Lewis and colleagues' [12] model, there was a partner 
effect such that individuals whose partners reported more frequent discussions of screening reported higher screening intentions. Note that it is in this final component of the model that the gender difference emerged. Specifically, constraining the association between husband's reports of discussing colorectal cancer screening in the past 6 months and wife's screening intention and the association between wife's reports of discussing screening in the past 6 months and husband's screening intention to the same value significantly worsened model fit, $\chi^{2}(1)=5.84, p=0.015$. As shown in the figure, the data are consistent with the notion that the wife's input concerning screening had a stronger relationship with the husband's screening intention (parameter estimate $=0.33$ ) than the husband's input had with the wife's screening intention (parameter estimate $=0.14$ ).

We also examined whether perceived colorectal cancer risk, decisional balance, and relational perspective had significant indirect associations with screening intentions using bootstrapping techniques (see Table 3). These tests indicated that although the indirect associations were relatively small, they were uniformly statistically significant. Given these results and the results in Fig. 2, these data are consistent with a pattern wherein (a) the relationship between perceived colorectal cancer risk and screening intentions was fully mediated by relational perspective and discussion frequency, (b) the relationship between relational perspective and screening intentions was fully mediated by discussion frequency, and (c) the relationship between decisional balance and screening intentions was partially mediated by relational perspective and discussion frequency.

\section{Discussion}

It is a widely held view that the marital relationship may be a key influence upon health behaviors. Despite this view, little is known about the role of the marital relationship in many health behaviors and even less is known about the role of the marital relationship in cancer screening decisions. In this study, we sought to achieve a better understanding of partner influence on colorectal cancer screening intentions using the interdependence model of behavior change by studying couples where neither partner was up to date with screening. Although these initial findings should be considered preliminary and need replication using a longitudinal approach, our results were largely consistent with this model. Most importantly, our findings suggest that couples' attitudes about screening were interdependent and that one partner's attitudes (e.g., decisional balance and perceived risk) and behavior (e.g., having a screening discussion) were associated with the other partner's screening intention. There was also evidence of joint effects [12]. That is, screening intentions were associated with both one's own attitudes as well as one's partner's attitudes. As has been noted in previous work [24], reciprocity is important. Because we found evidence of both actor and partner effects, both members of the couple have roles as agents and targets of influence. To some extent, screening intentions may be affected by relationship factors.

A key construct from the interdependence model is the transformation of motivation from an individual to a relationship level $[11,12]$. We assessed this construct by measuring the degree to which each partner believed that having his/her screening test was meaningful to the relationship and to the spouse and whether one's spouse's screening had implications for him/herself. This adoption of a relational perspective on one's motivation to have screening was indirectly associated with the other partner's screening intentions through a greater likelihood that the individual would engage in a discussion about colorectal cancer screening with their partner. That is, individuals who thought about their screening practices in terms of the behavior's implications for the relationship were more likely to report discussing screening with their partner, and the partner also reported more frequent screening discussions with that individual. Furthermore, this relational perspective was associated with 
higher screening intentions for both oneself and one's partner through its indirect association with couples' discussions, providing further evidence that transformation of motivation is associated with screening intentions.

The relationship between couples' reports of discussions about screening in their respective screening intentions revealed sex differences. Wives' reports of discussions with their husbands about screening had stronger association with husbands' screening intentions than husbands' reports of screening discussions had on the wives' screening intentions. This gender difference is consistent with previous reviews suggesting a stronger influence effect for wives upon their husbands than husbands upon their wives [25]. One explanation for this finding is that wives use influence strategies that are more interdependent (e.g., more positive and direct) [16]. Because the discussion measure used in this study did not evaluate the content of these discussions, it is not possible to discern whether these associations represent actual sex differences in the effects of partner influence strategies or differences in the types of influence husbands and wives employ during these discussions. That is, wives may use more positive influence strategies such as direct requests and fewer negative strategies (i.e., pressure) than husbands during their discussions with their partners. Another explanation is that wives are more likely to have a transformation of motivation to a relational perspective. However, our findings did not suggest that partners' level of relational perspective differed, so this is not a likely explanation of the gender difference.

Among the individual level factors, two associations were consistent with our predictions in that decisional balance and perceived risk were both associated with a greater relational perspective on screening. We also found that decisional balance was directly associated with higher screening intentions. The role of decisional balance in screening intentions and practices is well known, with a broad number of studies suggesting that greater perceived benefits and fewer perceived barriers are strong correlates of screening [4, 26, 27]. Our findings confirm previous work suggesting that benefits and barriers factors are strongly associated with screening intentions. However, we did not find a direct association between perceived risk and screening intentions. The role of perceived risk in screening decisions has been inconsistent in previous studies with some studies suggesting a direct role $[26,27]$ and other studies suggesting that the role of risk in intentions is more complex [4]. This study adds to the literature by suggesting that, if an individual believes that there is a threat to his or her own health (perceived risk) and if the individual perceives greater benefit in changing his or her own screening behavior (decisional balance), he or she is more likely to adopt a relational perspective on cancer screening. It is also interesting to note that greater perceived risk had a direct association with the likelihood of screening discussions as well as an indirect association with discussions via a greater likelihood of adopting relational perspective. Both risk and decisional balance had indirect associations with intentions via relational factors (relational perspective and couple discussions) as well as direct effects on intentions.

Although we originally hypothesized that higher marital quality would predict a greater likelihood that partners would adopt a relational perspective on colorectal cancer screening, the findings were not consistent with this prediction. Marital quality was not associated with the adoption of a relational perspective or with a greater likelihood that a partner would initiate discussions about having screening. It is possible that the lack of an association is due to the brief marital quality measure. Future studies may benefit from using a more comprehensive measure of marital quality (e.g., the Dyadic Adjustment Scale) to evaluate this possibility.

Looking at the model as a whole, individual attitudes were associated with relationship attitudes (relational perspective on screening) and relationship behaviors (screening 
discussions). These findings suggest that individual-level attitudes are associated with relational perspectives and attitudes as has been proposed by the interdependence model [12]. The findings are also consistent with the limited research on this topic [18] suggesting that the more that one partner wants to change his or her behavior, the more that he or she uses positive influence strategies with his or her partner.

Before discussing conclusions and future directions, it is important to point out limitations. Most importantly, this is a cross-sectional study and therefore we cannot rule out the possibility that couples' discussions influenced individual attitudes about screening or the likelihood that partners are able to see screening on relationship terms, and/or that screening intentions influenced the likelihood that couples initiated discussions with one another about screening. Second, as mentioned previously, we did not evaluate specific influence strategies couples engaged in during their discussions with one another. Third, our sample was primarily Caucasian, over half of the sample was retired, all were English-speaking, and most of the sample had medical insurance which may have influenced the study's results. However, we estimated the model allowing for each partner's insurance status to have a direct effect on his or her screening intentions, and neither of these effects was statistically significant. Moreover, including insurance status did not alter the other parameter estimates in the model. ${ }^{1}$ Discussions about cancer screening may be more prevalent among Caucasians and/or retired couples and intentions are likely to be higher among the insured. Fourth, we did not include other individual attitudes in the model that are known correlates of screening intentions (e.g., cancer worry and commitment to screening). Fifth, we assessed couples who were not compliant with screening. It is possible that the nature and magnitude of the associations between individual attitudes, relational perspectives, and screening discussions, and ultimately screening intentions, would be very different if discordant couples or couples who were both adherent with screening were studied. For example, negative tactics may be more prevalent when one partner has not had screening and the other has, and therefore screening discussions may not have a positive association with intentions, lower associations between attitudes on relational perspective, and/or lower levels of joint effects. It also would have been very interesting to compare the relational perspective on screening among couples who were both compliant with couples who were both noncompliant. Sixth, the measure of relational perspective was developed specifically for this study and should be validated in future work. Finally, we did not compare the role of the interdependence model with other health behavior change models that include the social environment. For example, the theory of reasoned action [28, 29] includes social norms, and it would have been useful to determine if the interdependence model explained more variance in colorectal cancer screening intentions.

Future research should consider a longitudinal design, assess couple influence strategies, and evaluate actual couple discussions about screening for a more fine grained analysis of partner effects. In conclusion, this study has illustrated that adopting a dyadic perspective on colorectal cancer screening decisions may yield a unique understanding of screening intentions. If we can better understand couples' reciprocal influences, we may be able to develop more effective screening interventions that harness these important influences on health outcomes.

\footnotetext{
${ }^{1}$ The correlation between insurance status and each of the variables included in the model were small and non-significant with the exception of the correlation between the husband's insurance status and whether the husband discussed screening with his wife $(r=0.19, p=0.36)$.
} 


\section{Acknowledgments}

We would like to acknowledge Knowledge Networks, and in particular Stefan Subias, for their assistance in this project. Sara Worhach provided project management and Kristen Sorice assisted with data preparation. This work was funded by grant CA 1503702.

\section{References}

1. American Cancer Society. Cancer Facts and Figures. Atlanta: American Cancer Society; 2011. Available at http://www.cancer.org/Research/CancerFactsFigures/index [Accessed 12 April 2011]

2. US Dept of Health and Human Services. Healthy People. Washington, DC: US Dept of Health and Human Services, Office of Population Affairs; 2010. Available at http://www.healthypeople.gov/ 2010/ [Accessed 12 April 2011]

3. Beydoun HA, Beydoun MA. Predictors of colorectal cancer screening behaviors among averagerisk older adults in the United States. Cancer Causes Contr. 2008; 9:339-359.

4. McQueen A, Vernon SW, Rothman AJ, Norman GJ, Myers RE, Tilley BC. Examining the role of perceived susceptibility on colorectal cancer screening intention and behavior. Ann Behav Med. 2010; 40:205-217. [PubMed: 20658212]

5. Madlensky L, Esplen MJ, Gallinger S, McLaughlin JR, Goal V. Relatives of colorectal cancer patients: Factors associated with screening behavior. Am J Prev Med. 2003; 25:87-94.

6. Manne S, Markowitz A, Winawer S, Meropol NJ, Haller D, Rakowski W, Babb J, Jandorf L. Correlates of colorectal cancer screening compliance and stage of adoption among siblings of individuals with early onset colorectal cancer. Health Psych. 2002; 21:3-15.

7. Harris JN, Hay J, Kuniyiki A, Asgari MM, Press N, Bowen DJ. Using a family systems approach to investigate cancer risk communication within melanoma families. Psych Onc. 2010; 19:1102-1111.

8. Falba TA, Sindelar JL. Spousal concordance in health behavior change. Health Serv Res. 2008; 43:96-116. [PubMed: 18211520]

9. Kolonel LN, Lee J. Husband-wife correspondence in smoking, drinking, and dietary habits. Am J Clin Nutr. 1998; 34:99-104. [PubMed: 7446465]

10. Wilson SE. The health capital of families: An investigation of the inter-spousal correlation in health status. Soc Sci Med. 2002; 55:1157-1172. [PubMed: 12365528]

11. Lewis, MA.; DeVellis, BM.; Sleath. Social influence and interpersonal communication in health behavior. In: Glanz, DK.; Rimer, BK.; Lewis, FM., editors. Health behavior and health education: Theory, research, and practice. 3. San Francisco: Jossey-Bass; 2002. p. 240-264.

12. Lewis MA, McBride CM, Pollak KI, Puleo E, Butterfield RM, Emmons KM. Understanding health behavior change among couples: An interdependence and communal coping approach. Soc Sci Med. 2006; 62:1369-1380. [PubMed: 16146666]

13. Kelley, HH.; Berscheid, E.; Christensen, A.; Harvey, JH.; Huston, TL.; Levinger, G., et al. Analyzing close relationships. In: Kelley, HH.; Berscheid, E.; Christensen, A.; Harvey, J.; Huston, TL.; Levinger, G., et al., editors. Close relationships. San Francisco, CA: Freeman; 1983. p. 20-67.

14. Kelley, HH.; Thibaut, TW. Interpersonal relations: A theory of interdependence. New York: Wiley; 1978.

15. Rusbult, CE.; Van Lange, PAM. Interdependence processes. In: Higgins, ET.; Kruglanski, AW., editors. Social psychology: Handbook of basic principles. New York: The Guilford Press; 1996. p. 564-596.

16. Lewis MA, Butterfield R, Darbes L, Johnston-Brooks CH. The conceptualization and assessment of health-related social control. J Soc Pers Rel. 2004; 21:669-687.

17. Franks MM, Rook KS, Keteyian SJ, Stephens MA, Franklin BA, Artinian NT. Spouses' provision of health-related support and control to patients participating in cardiac rehabilitation. J Fam Psychol. 2006; 20:311-318. [PubMed: 16756407]

18. Butterfield R, Lewis M. Health-related social influence: A social ecological perspective on tactic use. J Soc Pers Rel. 2002; 19:505-626.

19. Lewis MA, Butterfield R. Antecedents and reactions to health-related social control. Pers Soc Psych Bull. 2005; 31:416-427. 
20. Lewis MA, Rook KS. Social control in personal relationships: Impact on health behaviors and psychological distress. Health Psychol. 1991; 18:63-71. [PubMed: 9925047]

21. Rakowski W, Ehrich B, Dube CE. Screening mammography and constructs from the transtheoretical model: Associations using two definitions of stage of adoption. Ann Behav Med. 1996; 18:91-100. [PubMed: 24203691]

22. Sharpley CE, Rogers HJ. Preliminary validation of the Abbreviated Spanier Dyadic Adjustment scale: Some psychometric data regarding a screening test of marital adjustment. Educ Psych Meas. 1984; 44:1045-1050.

23. Kenny, DA.; Kashy, DA.; Cook, WL. Dyadic data analysis. New York: Guilford Press; 2006.

24. Miller, GR.; Bostner, F. Persuasion in personal relationships. In: Duck, S., editor. A handbook of personal relationships. New York: Wiley; 1988. p. 275-288.

25. Cutrona, C. Social support in couples. Thousand Oaks, CA: Sage Publications; 1996.

26. Gregory TA, Wilson C, Duncan A, Turnbull D, Cole SR, Young G. Demographic, social cognitive and social ecological predictors of intention and participation in screening for colorectal cancer. BMC Pub Health. 2011; 11:38. [PubMed: 21232156]

27. Power E, Van Jaarsveld C, McCaffery K, Miles A, Atkin W, Wardle J. Understanding intentions and action in colorectal cancer screening. Ann Beh Med. 2008; 35:285-294.

28. Ajzen, I.; Fishbein, M. Understanding attitudes and predicting social behavior. Englewood Cliffs, NJ: Prentice-Hall; 1980.

29. Fishbein, M.; Ajzen, I. Belief, attitude, intention, and behavior: An introduction to theory and research. Reading, MA: Addison-Wesley; 1975.

30. Krosnick, J.; Chang, L. A comparison of the random digit dialing telephone survey methodology with internet survey methodology as implemented by Knowledge Networks and Harris Interactive. Conference of the American Association for Public Opinion Research; 2001; Montreal, Canada.

31. Dennis M. Are internet panels creating professional respondents? The benefits of online panels far outweigh the potential for panel effects. Marketing Research. 2001; 13(Summer):34-38. 


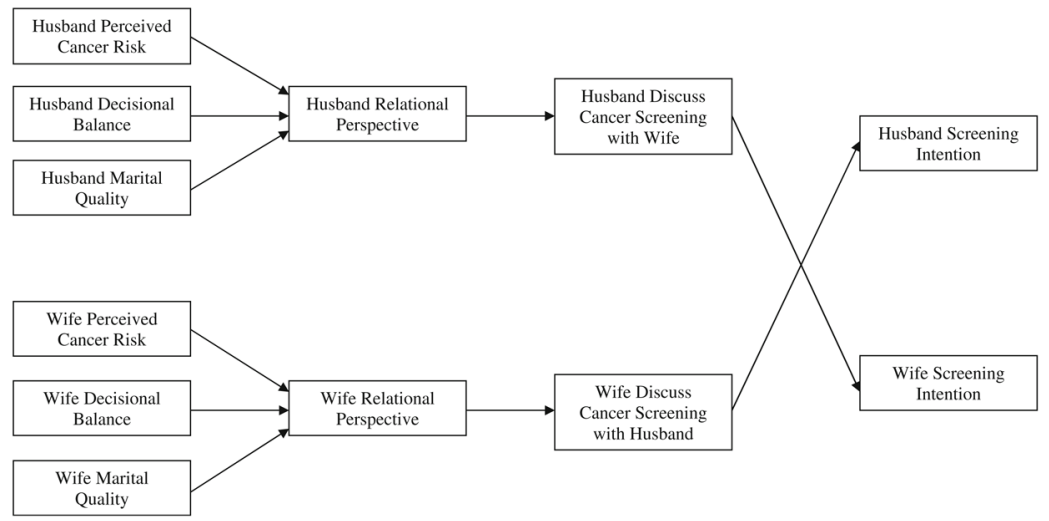

Fig. 1.

Proposed model depicting associations between individual attitudes, relational perspective, spousal influence, and screening intentions. Note: Cancer risk refers to colorectal cancer risk, and cancer screening refers to colorectal cancer screening 


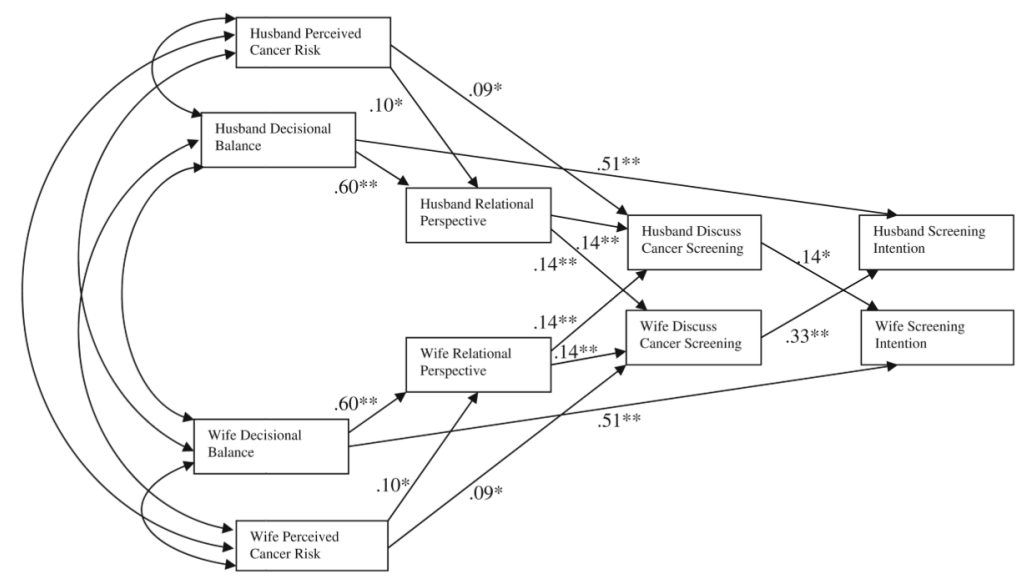

Fig. 2.

Final model depicting associations between individual attitudes, relational perspective, spousal influence, and screening intentions. Note: Cancer risk refers to colorectal cancer risk, and cancer screening refers to colorectal cancer screening. Standardized beta coefficients are shown. Although not depicted in the figure, the residual variances for each endogenous variable were allowed to correlate across spouses. $*^{*}<0.05$; $* * p<0.01$ 
Table 1

Descriptive information on study sample

\begin{tabular}{|c|c|c|c|c|}
\hline \multirow[t]{2}{*}{ Variable } & \multicolumn{2}{|l|}{ Husbands } & \multicolumn{2}{|l|}{ Wives } \\
\hline & $N(\%)$ & $M(\mathbf{S D})$ & $N(\%)$ & $M(\mathbf{S D})$ \\
\hline Age & & $60.1(7.6)$ & & $58.6(7.3)$ \\
\hline \multicolumn{5}{|l|}{ Ethnicity } \\
\hline Caucasian & $151(89.9)$ & & $154(91.7)$ & \\
\hline Black (non-Hispanic) & $9(5.4)$ & & $8(4.8)$ & \\
\hline Other (non-Hispanic) & $5(3.0)$ & & $4(2.4)$ & \\
\hline Hispanic & $2(1.2)$ & & $2(1.2)$ & \\
\hline$>2$ races (non-Hispanic) & $1(0.6)$ & & 0 & \\
\hline \multicolumn{5}{|l|}{ Education } \\
\hline Less than high school & $20(11.9)$ & & $14(8.3)$ & \\
\hline Completed high school & $58(34.5)$ & & $72(42.9)$ & \\
\hline Some college & $56(33.3)$ & & $52(31.0)$ & \\
\hline Bachelor degree or higher & $34(20.2)$ & & $30(17.9)$ & \\
\hline \multicolumn{5}{|l|}{ Employment status } \\
\hline Full time & $78(46.5)$ & & $58(34.5)$ & \\
\hline Part time & $13(7.7)$ & & $29(17.3)$ & \\
\hline Retired/does not work outside home & $57(33.9)$ & & $57(33.9)$ & \\
\hline Unemployed & $19(11.3)$ & & $23(13.7)$ & \\
\hline Missing & $1(0.6)$ & & $1(0.6)$ & \\
\hline Medical insurance (yes) & $138(82.1)$ & & $141(83.9)$ & \\
\hline
\end{tabular}




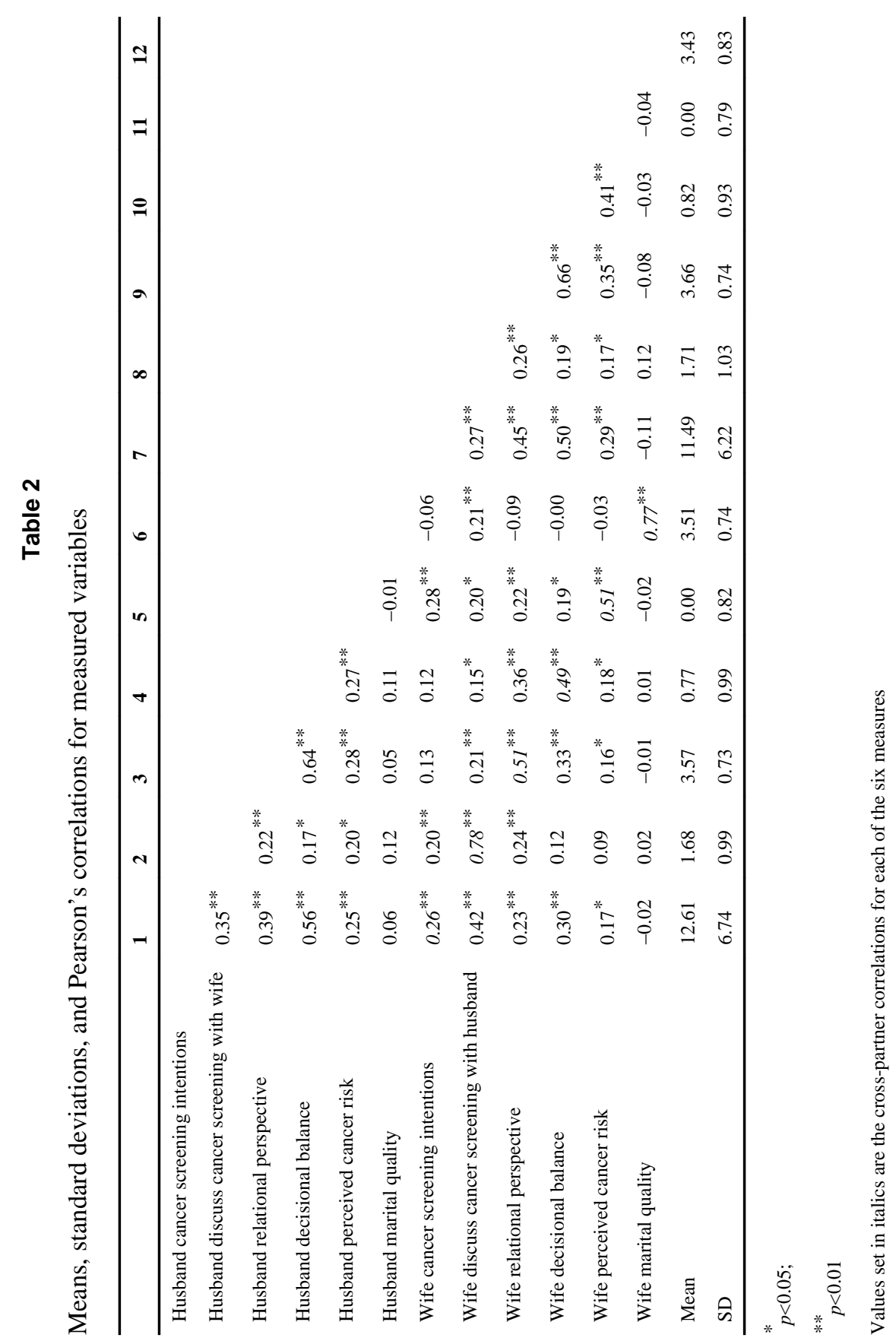

Ann Behav Med. Author manuscript; available in PMC 2014 January 23. 


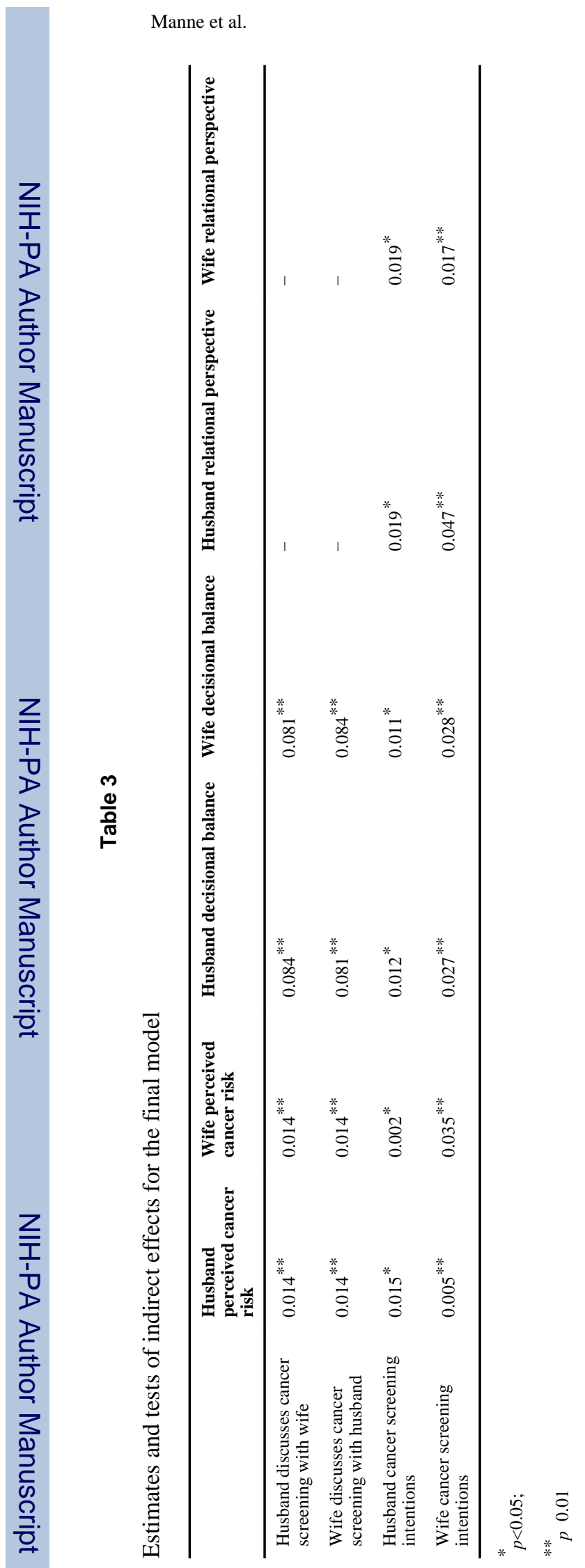

Ann Behav Med. Author manuscript; available in PMC 2014 January 23. 